\title{
Can Artificial Intelligence Enhanced Robotic Teaching Assistant Be a Game Changer in Enhancing Classroom Engagement and Learning Among Undergraduate Students in Our Higher Education Institutes?
}

\begin{abstract}
Andy Shome
Alfred University

The author has taught Business and Management courses in four different types of higher education institutes across four separate states in the United and has noticed a common trend among undergraduate students. There is deep reluctance to read academic content and remain engaged in the classroom among a significantly large number of the students. The author would like to examine whether an Artificial Intelligence enhanced "chat-bot" can help improve engagement and improve course performance in classrooms.
\end{abstract}

Keywords: AI, AI and pedagogy, innovative pedagogy, AI in education, AI in higher education

\section{INTRODUCTION TO THE PROBLEM}

The author's experience ranges from a small liberal arts college in rural Ohio, a pro-profit College in urban Colorado, a midsize land-grant university in small town Idaho and a private not for profit university in a small town in New York State. While the lack of motivation varies from a third of the cohort to half of the cohort, the trend is common in all of the classrooms, irrespective of the state and background of the students.

The author's experience is limited to undergraduate management students alone. The common trends that he has noticed can be are broadly classified as a reluctance to buy textbooks, overdependence on Google for research, acquisition of knowledge over digital devices, low level of motivation to listen to lectures, reluctance to take notes during class hours, high level of distraction from media rich cellphones/ computing devices and an inability to manage time.

\section{CONTEXT FOR THE PROBLEM}

The near $100 \%$ penetration of smart-phones and reluctance to buy textbooks was posing profound challenges to students with low motivation, in the author's classroom. The primary issue seems to be an unwillingness to acquire, analyze data and inability to manage time. All of these issues were compounded by the lack understanding of how the classroom processes help them learn skills, which are valued in the marketplace for example research, analysis and rhetoric.

The research for an innovative solution led the author to published literature from multiple educators namely Glasser (1986), who argued in favor of student led teaching in classroom as it helped students learn and engage with the material. Professor Fraser (2011), at McGill University, demonstrated that her class 
created a high-performance, "active learning" environment by placing groups of students together as learning teams. Prensky (2001) pointed out that there has been a fundamental change in the students of today, whom he termed "Digital Natives", and he argued that our education system was not geared for their needs, especially around acquiring knowledge. Professor Mazur (Lambert, 2012) pointed out at the remarkable growth in learning when students were encouraged to teach each other in his classrooms at Harvard University, at the cost of extended lectures.

\section{Emerging Solutions Based on Data Gathered From Classroom Observation}

The author has conducted multiple interviews among his students across all four institutions of higher education. However, low achieving students have consistently refused to grant an interview so that author has been limited to learning about the behaviors of low motivated students by interviewing their highly motivated team members. This type of interviews has been possible because the students work in teams of three members in his classrooms most of the time. These teams have been termed as Learning Teams (LTs) in his classroom. The author has borrowed the concept from undergraduate classes at Harvard University, USA and McGill University Canada (Fraser, 2011).

The author acknowledges the limitations in his research but there is a silver lining that is emerging out of these interviews. The 18-21-year-old undergraduate students do not want to miss significant number of classes or avoid work. They are quite surprised when they lose track of time and realize how far behind, they are in the course. But when they are made aware, and try their best to catchup, they are overwhelmed by the workload they have missed. So there does not seems to be a deep apathy towards the workload but a miss-management of time needed to manage the workload.

On the other hand, the author's research in the efficacy of Artificial Intelligence (AI) robots (bots) in education (Holmes, Bialik \& Fadel, 2019) has informed that an AI bot may be able to provide personalized reminder and tutorial service to students and help them to catchup with the workload in time, and help them achieve good quality performance in courses.

Given that the students-on low motivation- is made aware of the loss of time and grades in the course and will try to catchup with 16 weeks' material in the last 2-3 weeks, the AI bot may be invaluable in gathering the required material, lecture videos and hands-on coaching for the student to pass the course and even manage a decent grade. The exciting part of this solution is that the AI bot can offer personalized and adaptive education (Holmes, Bialik \& Fadel, 2019) at massive scale to improve students' engagement and participation as well as performance in Business Management education.

\section{Proposed Solution Based on Data Gathered From Classroom Observation}

The author's research is centered on two approaches. The first part is to enhance his pedagogy with a TA bot enhanced with AI and machine learning. The second part is to leverage the strength of the AI bot to provide an education plan that is personalized to a single student. The author believes that "hyperpersonalization" of education plan will allow the author to help each student with a program for success in classroom. To this effect the AI bot can analyze and implement a lesson plan that is hyper-personalized to each student. For instance, a student can use multiple trials to write a paper before final submission as the AI bot can correct the paper over and over again without any major problems. At this stage the AI bot may not have the capability to grade content of the paper but has the ability to correct the structure of the paper (APA6 compliance for example). However, if the author can train a human TA on how to correct a paper, he can train an AI bot to correct papers too. Furthermore, over time machine learning can help AI to learn the numerous common mistakes made by students while writing a paper. This capability will only grow over time as the machine is fed a continuous stream of mistakes made by students and how to correct them. That capability will save the author a lot of time so that he can focus on the depth of content and research demonstrated by the students.

\section{Challenges Faced in Implementation}

The author has progressed quite extensively into the Literature Review but has been confronted with a few important challenges. Funding for the initial trial AI Bot runs into thousands of dollars and sourcing 
large number of students' papers with corrected mistakes to feed the machine and help it learn answers for common mistakes. The author hopes that the peer group in this conference will help him find solutions to his challenges and provide guidance for improving his research strategy.

\section{CONCLUSION}

In conclusion, the author hopes to acquire funding for the research project. Provide the experimentation group with the AI enabled Robotic TA and simultaneously run a control group with the TA. The results of the two cohorts would be compared and contrasted to examine the efficacy of the AI enabled TA. The author would then share his methodology and learning from his classroom with the wider group of participants in the conference and invite their opinion and understanding to help him arrive at an improved Research Strategy for further research. The author would gather detailed data and analyze the data to so that he can help the students to meet their own challenges and disseminate the knowledge to add to the literature available to educators worldwide via peer edited academic publications.

\section{REFERENCES}

Chi, M.T.H., Bassok, M., Lewis, M., Reimann, P., \& Glaser, R. (1989). Self-Explanations: How Students Study and Use Examples in Learning to Solve Problems. Cognitive Science, 13(2), 145-182. Retrieved from http://chilab.asu.edu/papers/ChiBassokLewisReimannGlaser.pdf

Fraser, W. (2011, March 15). Teaching and learning services. Teaching and Learning Experiences in Active Learning Classrooms: Highlights. Retrieved from https://www.youtube.com/watch?v=xFIDad64j8M

Holmes, W., Bialik, M., \& Fadel, C. (2019). Artificial Intelligence in Education. Promise and Implications for Teaching and Learning. The Center for Curriculum Redesign. Boston, MA.

Lambert, C. (2012). Twilight of the lecture. Harvard Magazine. Retrieved from http://harvardmagazine.com/2012/03/twilight-of-the-lecture

Prensky, M. (2001). Digital Natives, Digital Immigrants Part 1. On the Horizon, 9(5), 1-6. doi:10.1108/10748120110424816 